\title{
HEIGHT AND WEIGHT IN RELATION TO ONSET OF PUBERTY IN BOYS
}

\author{
BY \\ RICHARD W. B. ELLIS, O.B.E., M.D., F.R.C.P. \\ Professor of Child Life and Health, University of Edinburgh
}

(With the technical assistance of LUIS SANZ, B.Sc.)

The great majority of studies of growth in relation to puberty have been carried out on girls, since the onset of menstruation provides a fixed point which can be accurately recorded, whilst the age of establishment of a regular menstrual cycle can also be determined in most cases within comparatively narrow limits. Although the onset of menstruation does not necessarily correspond with the onset of ovulation, and has indeed tended to obscure the fact that puberty is actually a period of transition from childhood to adolescence rather than a single fixed point, its use for statistical purposes has thrown considerable light on the relationship of growth to early or late maturity. Thus Flory (1935) and others have found that girls who menstruated early showed radiological evidence of more advanced osseous development (e.g. appearance of the sesamoid on the distal end of the first metacarpal) than non-pubescent children of the same age, whilst Stone and Barker (1937) described an early slowing-down of growth in girls who had menstruated early, and found that, after the age of sixteen, girls who had not menstruated were in fact taller than those in whom the menarche had occurred.

In the case of boys there is no fixed point corresponding to the onset of menstruation which can be accurately determined, and it is probable that spermatogenesis is more gradually established than ovulation. Assays of excretion of 17-ketasteroids (Nathanson et al., 1939, 1941 ; Talbot et al., 1943) also suggest that this is of gradual increase, with a wide normal variation, and although excretion of gonadotrophic hormone in the urine shows a general tendency to increase with increasing maturity (Catchpole et al., 1938) it cannot as yet be said to provide an accurate index of onset of puberty. The appearance of pubic hair, though usually an early sign of pubescence, bears no very constant relationship to genital development, whilst other secondary sexual characters, e.g. skin and voice changes, are all gradual in onset.

By considering the various clinical manifestations of puberty together, however, it is possible even in boys to establish grades of maturity, and to classify groups of boys into these with some degree of accuracy. Greulich et al. (1942) have described five such maturity-groups. Although the classical mono- graph of these authors was not available when the present study was carried out, it was found subsequently that closely similar criteria for grading had been established independently; in the present study, however, only three maturity-groups have been compared, the 'prepubescent' group corresponding approximately with Greulich's Grades 1 and 2, the 'pubescent' with Grade 3, and the 'adolescent' with Grades 4 and 5.

The purpose of the present investigation was to determine whether any significant difference in mean height and weight of boys in the same age-groups but in different maturity-groups could be demonstrated and, if so, how far back these differences were manifest. At the same time it was possible to make certain observations on the order of appearance and character of some of the changes associated with puberty.

\section{Present Investigation}

Clinical material. This consisted of two hundred and eight healthy boys between the ages of eleven and sixteen years. All boys who had had prolonged or recent illness likely to have affected their growth were excluded, as were any showing cryptorchidism. No other cases of endocrine disturbance or pathological obesity were encountered. The boys were derived from two residential schools, in both cases situated in country surroundings and providing a liberal diet. In all cases, detailed medical records were available.

In School A, the boys entered from foster-homes at the age of five, being weighed and measured by trained personnel on entry and thereafter in January of each year, or more frequently. Until 1945, all the boys had remained at school during the holidays, and had received the same school diet. This group was, therefore, exceptionally well controlled from the point of view of an investigation of this type, and measurements were available in every case from the sixth year.

In School B, the boys entered from their homes at various ages from eight years onward, and were weighed and measured by trained personnel at least three times a year. They received the same diet at school, but returned home for the holidays.

Although the living conditions and diet in the two schools were comparable, it was considered best to compare measurements only of boys from the same school. Whilst this renders the individual 
groups smaller, it reduces a number of possible errors. Thus the boys in the two schools were derived from somewhat different stock, whilst the social conditions in the immediate pre-school years were probably more uniform in the case of School A than of School B.

Age-groins. The boys were divided into yearly groups, i.e. $11+$ to $12,12+$ to 13 , etc., a birthday falling on the date of the examination placing the boy in the younger age-group. In the case of School A, where the exact date of each previous measurement was known, the ages were calculated throughout on the basis of years plus days; in the case of School B, where the month but not the exact date of the previous examinations was recorded, ages were calculated to the nearest month. The age-groups examined in the two schools were as follows :

$\begin{array}{ccc}\text { Age (years) } & \text { School A } & \text { School B } \\ 11 \text { to } 12 & 26 & - \\ 12 \text { to } 13 & 39 & - \\ 13 \text { to } 14 & 45 & 28 \\ 14 \text { to } 15 & 16 & 28 \\ 15 \text { to } 16 & 4 & 22\end{array}$

Some of these groups were too small, or insufficiently divided on a maturity-grading, to make comparisons possible; the age-groups selected for analysis were 12 to 13 (School A), 13 to 14 (Schools A and B), 14 to 15 (School B), and 15 to 16 (School B).

Meas rements. Heights were measured with the boys standing barefoot against a stationary measure with sliding head-arm, and were recorded either to the nearest $\frac{1}{4}$ inch (and converted into $\mathrm{cm}$.) or to the nearest $0.5 \mathrm{~cm}$. Leg-length was measured with a steel tape, from the anterior superior iliac spine to the tip of the internal malleolus, and recorded to the nearest $0.5 \mathrm{~cm}$. Weights were measured on lever balances that had been regularly checked, were recorded to the nearest $\frac{1}{\mathrm{lb}}$. and converted to the metric scale. All calculations are based on the naked weight.

Eromination. A record was made of the presence and extent of pubic, axillary, facial, and body hair; the stage of development of the genitalia; and the appearance of the skin, with particular reference to the presence of comedones or acne and the development of the sebaceous and apocrine sweat glands. It was not found practicable to estimate early changes in the pitch of the voice on a single examination or without special apparatus, though in those cases where the voice was obviously 'broken' the fact was recorded. The presence or absence of gynaecomastia was noted in all cases.

PUBIC HAIR. This was recorded as PO when the pubic area showed only the presence of the fine body-hair of early childhood, or the slightly longer, non-pigmented vellus which precedes the appearance of true pubic hair. P1 was used to describe the appearance of one or more coarse, pigmented hairs at the base or sides of the penis; P2 when pigmented hairs extended across the root of the penis; P3 when approximately half the pubis was covered; P4 when the area of female distribution was covered, and hairs extended to the perineal or anal region; and P5 when hair was present on the linea alba, lower abdomen, or groins (cf. Godin, 1934).

AXILLARY HAIR. This was recorded as A0 (complete absence), A1 (the presence of one or more pigmented hairs), A2 (hairs more than $1 \mathrm{~cm}$. in length and extending over an area approximately
$2 \mathrm{~cm}$. in length), or A3 when the growth of axillary hair was profuse.

FACIAL HAIR. The significance of facial hair was found less easy to assess, since the appearance was greatly influenced by colouring or shaving. Typically the earliest appearance of fine hair was seen on the lateral parts of the upper lip, thence spreading toward the centre. Except in the most hirsute boys, it was only found practicable to classify facial hair as present or absent.

BODY HAIR. The posterior aspects of the forearms were examined for hair-growth, but it was again found that only in the most mature boys were the findings unequivocal.

Genitalia. Greulich et al. (1942) drew attention to three features of the male genitalia at puberty, which were also used as criteria of maturity-grading in the present study. The penis first increases considerably in length, and then subsequently in girth with development of the corpora cavernosa. The rapid increase in size of the testicles at puberty is not associated with a corresponding increase in size of the epididymis, with the result that the relative proportions of the two show a marked alteration from those of childhood; with increase in size the testicles also become softer. Thirdly, the scrotum, which in childhood is widest at its proximal end, becomes not only pendulous but wider at its distal end with the increased size of the testicles. (This last point was found easier to assess clinically than rugosity, which was very variable.)

In the present study, the stage of development of the penis and that of the testicles plus scrotum were separately assessed as 'prepubescent,' ' pubescent,' or 'adolescent.' (It was found that whereas the development of the scrotum followed closely that of the testicles, the testicles and penis were not necessarily developed to an equal extent.)

SkIN. The skin of the cheeks, roots of the nose, and base of the lower lip was examined for comedones, and though their presence was found to be much higher after the onset of puberty, it was not itself taken as a criterion of diagnosis. The group as a whole was remarkably free from acne, and though the few cases that were observed were all in the more mature boys, its presence or absence was of little help in grading. Development of the apocrine and sebaceous glands was also regarded as confirmatory rather than diagnostic.

GraDING. On the basis of the clinical examination, irrespective of age and size, each boy was graded as 'prepubescent,' 'pubescent,' or 'adolescent.' The presence of pubic hair and/or pubescent genital development were taken as the criteria of pubescence. The presence of pubic hair, even when this was profuse, was not by itself taken as a criterion of adolescence; for this grading, well-marked increase in girth as well as length of the penis, and substantial development of the testicles were considered necessary.

In spite of the inherent difficulties which must arise over border-line cases (since one stage of development will pass gradually and not abruptly to the next), it appeared that grading on this basis was substantially valid. A second examination of a hundred and thirty-two of the boys was carried out one hundred days after the first, and a second assessment made without reference to the original one. It was found that in no instance was a boy given a lower grading on his second examination than on his 
first; eleven boys were given a higher grading in view of the advanced development that had occurred during the interval; and the remainder were placed in the same categories as before.

\section{Results}

Maturity in rebtion to age. The following analysis of the total number of boys examined (208) shows how the maturity-gradings are related to chronological age (table 1). As would be expected, the percentage of prepubescent boys steadily falls from the age of 11 to 15 , whilst the percentage of adolescents rises from 13 to 16 . The highest percentage of pubescent boys is seen in the 13- to 14-year-old group, which is also the group most evenly divided between prepubescent and pubescent.

Comparison of height and weight of maturity groups. In each of the age-groups selected, a comparison was made between the mean height and weight of those boys showing a more advanced degree of maturity with those showing less. Thus in the 12- to 13-year-old group (School A), the mean heights and weights of the 25 prepubescent boys were compared with those of the 14 pubescent boys. In the 13- to 14-year-old groups (Schools A and B), comparison was also made between the prepubescent boys and the pubescent, whilst in the 14 to 15 -yearold and 15- to 16-year-old groups (School B), comparison was made between the pubescent and adolescent groups. This initial comparison gave the results shown in table 2.

The probable errors were calculated for each comparison, and it will be seen from table 3 that the probability of the lower maturity-group being of greater height or weight than the higher maturitygroup of the same age is in no instance more than 1 in 10 , whilst in most instances it is considerably less.

It is thus clear from table 2 that the more mature boys are significantly taller and heavier than the less mature boys in the same age-group. Indeed, the more mature boys in each age-group are found to be taller and heavier than the less mature boys in the age-group immediately above them (e.g. the pubescent boys aged 12 to 13 compared to the prepubescent boys aged 13 to 14 , or the adolescent boys aged 14 to 15 compared with the pubescent boys aged 15 to 10. Further evidence that these differences in height and weight between boys of different grades of maturity in the same age-group cannot be attributed to such minor differences in mean age as existed between the maturity-groups is shown by reference to the growth curves given below, where the

TABLE 1

MATURITY IN RELATION TO AGE

\begin{tabular}{|c|c|c|c|c|c|c|c|}
\hline \multirow{2}{*}{ Age (years) } & \multirow{2}{*}{ Total } & \multicolumn{2}{|c|}{ Prepubescent } & \multicolumn{2}{|c|}{ Pubescent } & \multicolumn{2}{|c|}{ Adolescent } \\
\hline & & No. & Per cent. & No. & Per cent. & No. & Per cent. \\
\hline $\begin{array}{l}11 \text { to } 12 \\
12 \text { to } 13 \\
13 \text { to } 14 \\
14 \text { to } 15 \\
15 \text { to } 16\end{array}$ & $\begin{array}{l}26 \\
39 \\
73 \\
44 \\
26\end{array}$ & $\begin{array}{r}23 \\
25 \\
31 \\
6 \\
0\end{array}$ & $\begin{array}{c}88 \cdot 5 \\
64 \cdot 1 \\
42 \cdot 5 \\
13 \cdot 6 \\
0\end{array}$ & $\begin{array}{r}3 \\
14 \\
34 \\
11 \\
8\end{array}$ & $\begin{array}{l}11 \cdot 5 \\
35 \cdot 9 \\
46 \cdot 6 \\
25 \cdot 0 \\
30 \cdot 8\end{array}$ & $\begin{array}{r}\mathbf{0} \\
\mathbf{0} \\
\mathbf{8} \\
27 \\
18\end{array}$ & $\begin{array}{c}0 \\
0 \\
11 \cdot 0 \\
61 \cdot 4 \\
69 \cdot 2\end{array}$ \\
\hline
\end{tabular}

TABLE 2

COMPARISON OF HEIGHT AND WEIGHT OF MATURITY GROUPS

\begin{tabular}{|c|c|c|c|c|c|c|c|c|c|}
\hline \multirow{2}{*}{\multicolumn{3}{|c|}{ Age Group }} & \multirow{2}{*}{ School } & \multicolumn{3}{|c|}{ Height (cm.) } & \multicolumn{3}{|c|}{ Weight (kg.) } \\
\hline & & & & Mean & $\begin{array}{l}\text { Standard } \\
\text { error }\end{array}$ & $\begin{array}{l}\text { Standard } \\
\text { deviation }\end{array}$ & Mean & $\begin{array}{l}\text { Standard } \\
\text { error }\end{array}$ & $\begin{array}{l}\text { Standard } \\
\text { deviation }\end{array}$ \\
\hline $\begin{array}{l}12 \text { to } 13 \\
\text { 1. Prepubescent ... } \\
\text { 2. Pubescent }\end{array}$ & $\begin{array}{l}s \\
\cdots \\
\cdots\end{array}$ & $\because$. & $\begin{array}{l}\mathbf{A} \\
\mathbf{A}\end{array}$ & $\begin{array}{l}142 \cdot 10 \\
148 \cdot 01\end{array}$ & $\begin{array}{l}1.46 \\
1.69\end{array}$ & $\begin{array}{l}5 \cdot 26 \\
6 \cdot 09\end{array}$ & $\begin{array}{l}33 \cdot 32 \\
37 \cdot 74\end{array}$ & $\begin{array}{l}0.64 \\
1.39\end{array}$ & $\begin{array}{l}3.06 \\
6.66\end{array}$ \\
\hline $\begin{array}{r}13 \text { to } 14 \\
\text { 1. Prepubescent .. } \\
\text { 2. Pubescent } \quad . . \\
\end{array}$ & s & $\begin{array}{l}. \\
.\end{array}$ & $\begin{array}{l}\mathbf{A} \\
\mathbf{A}\end{array}$ & $\begin{array}{l}146 \cdot 30 \\
151 \cdot 53 \\
\end{array}$ & $\begin{array}{l}1.75 \\
1.39 \\
\end{array}$ & $\begin{array}{l}7.23 \\
6.93 \\
\end{array}$ & $\begin{array}{l}36 \cdot 30 \\
41 \cdot 49 \\
\end{array}$ & $\begin{array}{l}1.25 \\
1.13\end{array}$ & $\begin{array}{l}5.73 \\
5.63\end{array}$ \\
\hline $\begin{array}{l}13 \text { to } 14 \\
\text { 1. Prepubescent .. } \\
\text { 2. Pubescent }\end{array}$ & s. & $\because$. & $\begin{array}{l}\mathbf{B} \\
\mathbf{B}\end{array}$ & $\begin{array}{l}146 \cdot 53 \\
158 \cdot 88\end{array}$ & $\begin{array}{l}1.55 \\
1.55\end{array}$ & $\begin{array}{l}5 \cdot 59 \\
6 \cdot 20\end{array}$ & $\begin{array}{l}38 \cdot 33 \\
47 \cdot 73\end{array}$ & $\begin{array}{l}0.92 \\
1.41\end{array}$ & $\begin{array}{l}3 \cdot 31 \\
5 \cdot 64\end{array}$ \\
\hline \begin{tabular}{ll}
\multicolumn{1}{c}{14 to 15} \\
1. Pubescent & $\ldots$ \\
2. Adolescent & .
\end{tabular} & s & $\begin{array}{l}. \\
.\end{array}$ & $\begin{array}{l}\mathbf{B} \\
\mathbf{B}\end{array}$ & $\begin{array}{l}155.91 \\
163.83\end{array}$ & $\begin{array}{l}1 \cdot 19 \\
1.60\end{array}$ & $\begin{array}{l}3 \cdot 76 \\
6 \cdot 00\end{array}$ & $\begin{array}{l}46 \cdot 00 \\
52 \cdot 18\end{array}$ & $\begin{array}{l}1.12 \\
1.62\end{array}$ & $\begin{array}{l}3.55 \\
6.07\end{array}$ \\
\hline \begin{tabular}{l}
\multicolumn{1}{c}{15 to 16} \\
1. Pubescent \\
2 Adolescent
\end{tabular} & . & $\begin{array}{l}. . \\
. .\end{array}$ & $\underset{\mathbf{B}}{\mathbf{B}}$ & $\begin{array}{l}154 \cdot 53 \\
164 \cdot 31\end{array}$ & $\begin{array}{l}2.39 \\
2 \cdot 74\end{array}$ & $\begin{array}{r}6 \cdot 76 \\
10-29\end{array}$ & $\begin{array}{l}45 \cdot 30 \\
53 \cdot 59\end{array}$ & $\begin{array}{l}2 \cdot 11 \\
2 \cdot 14\end{array}$ & $\begin{array}{l}5.96 \\
8.00\end{array}$ \\
\hline
\end{tabular}


TABIE 3

\begin{tabular}{c|c|c|c}
\hline School & Age-group & $\begin{array}{c}\text { Probability that prepubescent mean } \\
\text { height greater than pubescent mean } \\
\text { height }\end{array}$ & $\begin{array}{c}\text { Probability that prepubescent mean } \\
\text { weight greater than pubescent mean } \\
\text { weight }\end{array}$ \\
\hline A & 12 to 13 & $\begin{array}{c}0-015 \\
0-094 \\
0-000\end{array}$ & $0-087$ \\
B & 13 to 14 & 13 to 14 & $\begin{array}{c}0.001 \\
0-000\end{array}$ \\
B & 15 to 15 & $\begin{array}{c}\text { Probability that pubescent mean height } \\
\text { greater than adolescent mean height } \\
0-000 \\
0-004\end{array}$ & $\begin{array}{c}\text { Probability that pubescent mean weight } \\
\text { greater than adolescent mean weight } \\
0-005 \\
0-034\end{array}$ \\
\hline
\end{tabular}

mean age of the group at the date of each measurement is shown graphically.

A further point of considerable interest which is brought out by these figures is that the boys who show evidence of the onset of puberty between 13 and 14 years of age (School B), are taller and heavier than those where puberty is beginning between 14 and 15 , and these again are taller and heavier than the boys graded as pubescent between 15 and 16 years. Although the differences in this instance are small, the observation suggests that the smallest boys are in fact those that tend to mature the latest.

Growth curves. In view of the above findings, growth curves (height and weight) were constructed for each group, and compared as before. Those for the boys in School A are the more complete, as all boys entered the school in their sixth year. In the case of boys from School B, where the age of entry varied from the eighth to the twelfth year, the curves have been contructed from the age at which

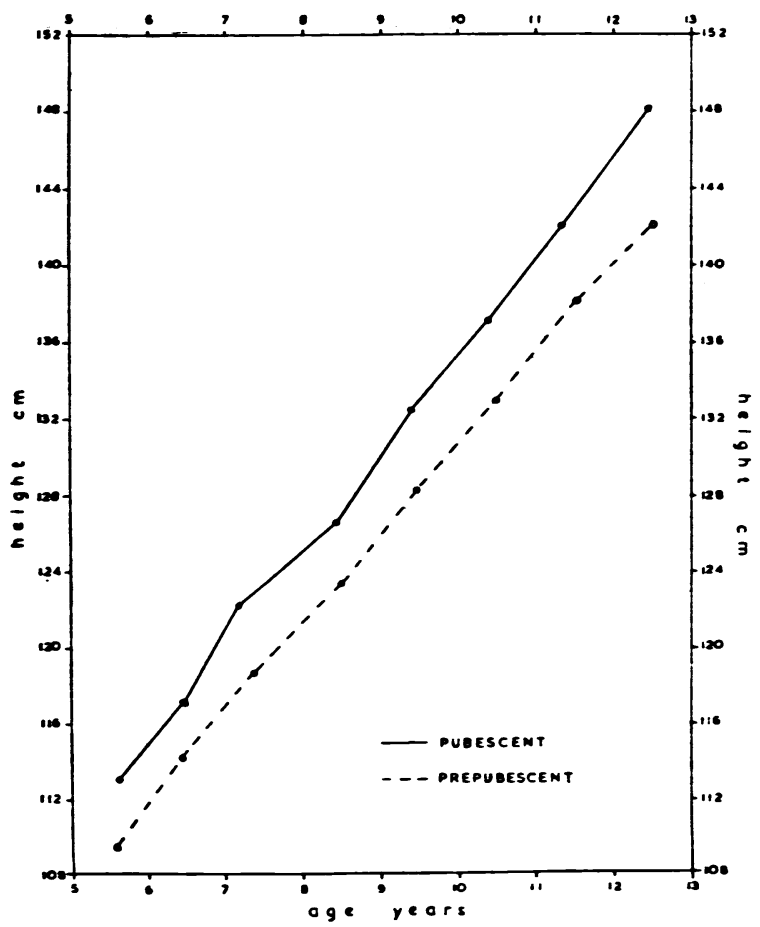

Fig. 1.-Mean height of boys aged 12 to 13 years at date of examination (School A), from the sixth to thirteenth year. they may be taken as representative of the complete group.

It will be seen from these figures that at every age for which mean values are available, the groups of boys who matured earlier are taller and heavier than their later-maturing contemporaries. This is particularly striking in the case of boys from School A (figs. 1 to 4) where the differences are demonstrable in the sixth year. In all cases the curves, particularly those of weight, tend to diverge with the establishment of puberty. Although the individual groups analysed are relatively small, the fact that the findings were similar in every instance tends to support their general validity.

Rate of growth during paberty. The maturitygradings used in the present study include in the 'prepubescent' group boys whose development is essentially that of childhood, and also those who may show the very earliest signs preceding the more manifest appearances of commencing maturity.

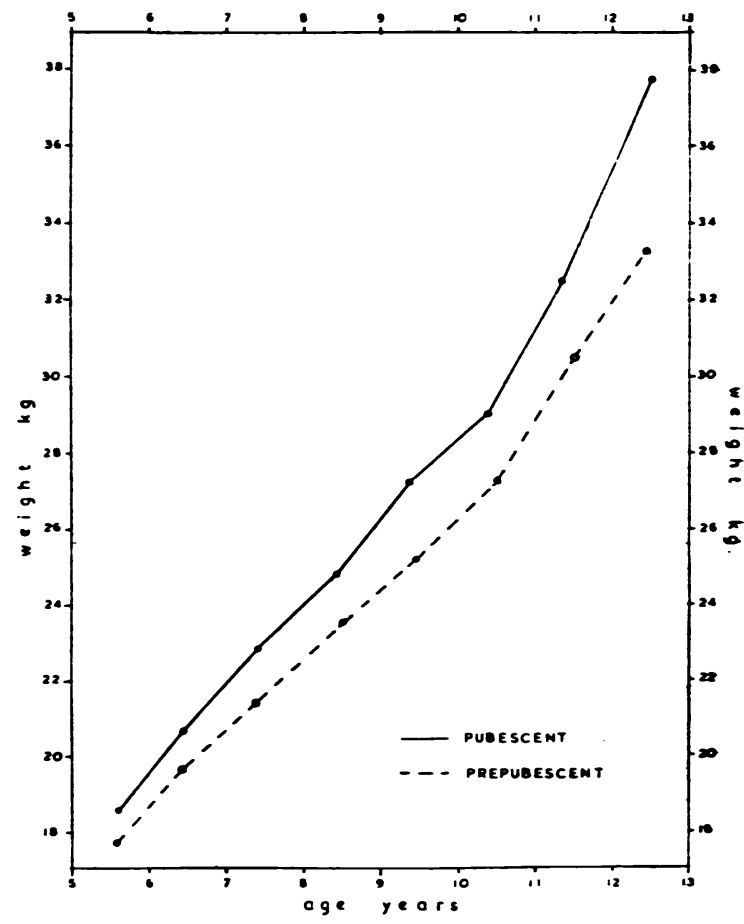

Fig. 2.-Mean weight of boys aged 12 to 13 years at date of examination (School A), from the sixth to thirteenth year. 


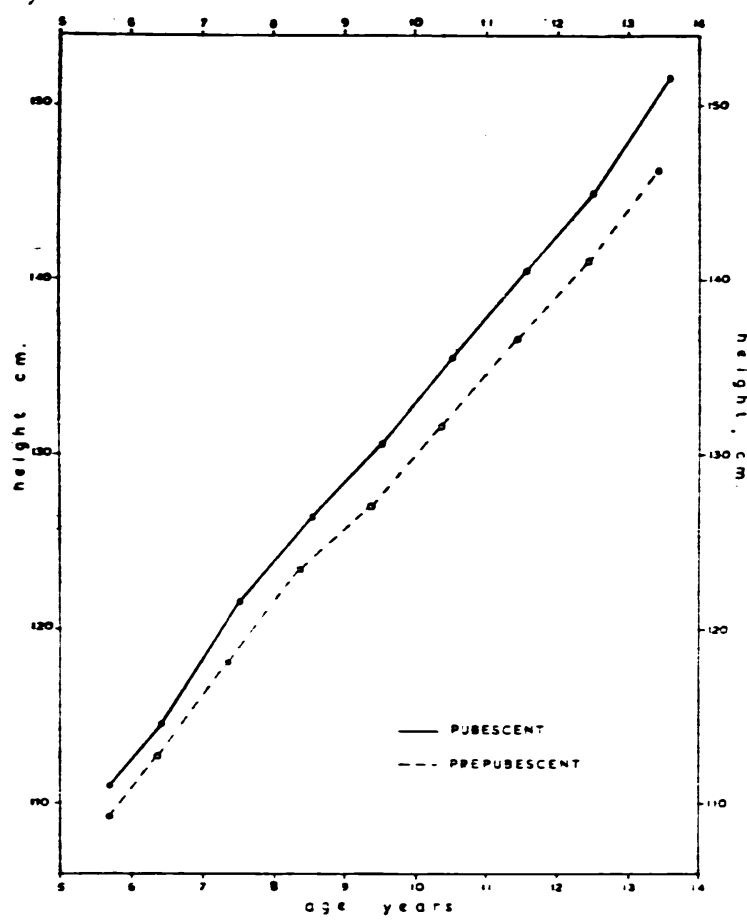

Fig. 3.-Mean height of boys aged 13 to 14 at date of examination (School A), from sixth to fourteenth year.

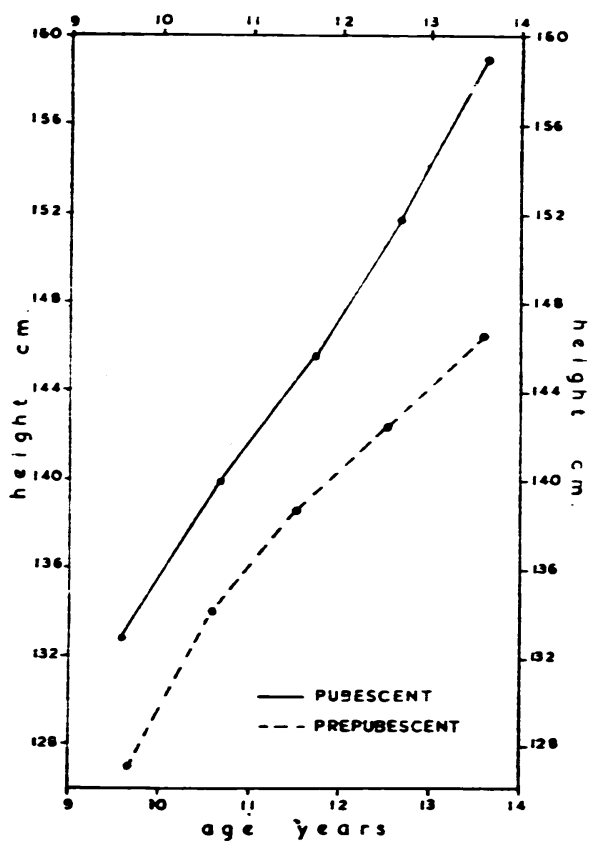

FIG. 5.

Figs. 5 and 6.-Mean height and weight of boys aged 13 to 14 years at date of examination (School B), from tenth to fourteenth year.

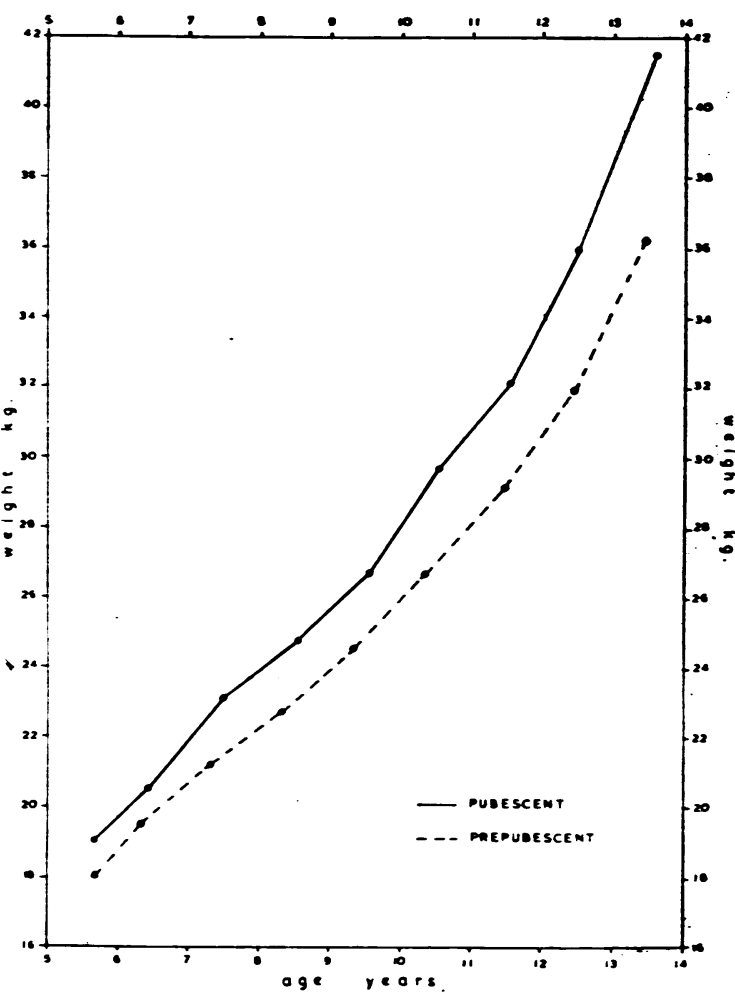

Fig. 4.-Mean weight of boys aged 13 to 14 at date of examination (School A), from sixth to fourteenth year.

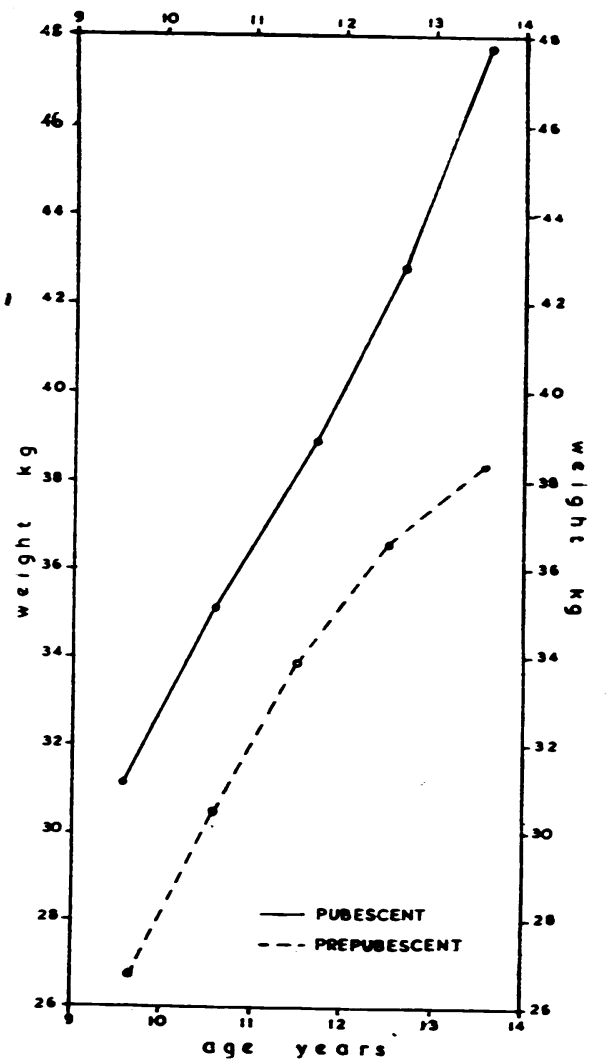

Fig. 6. 


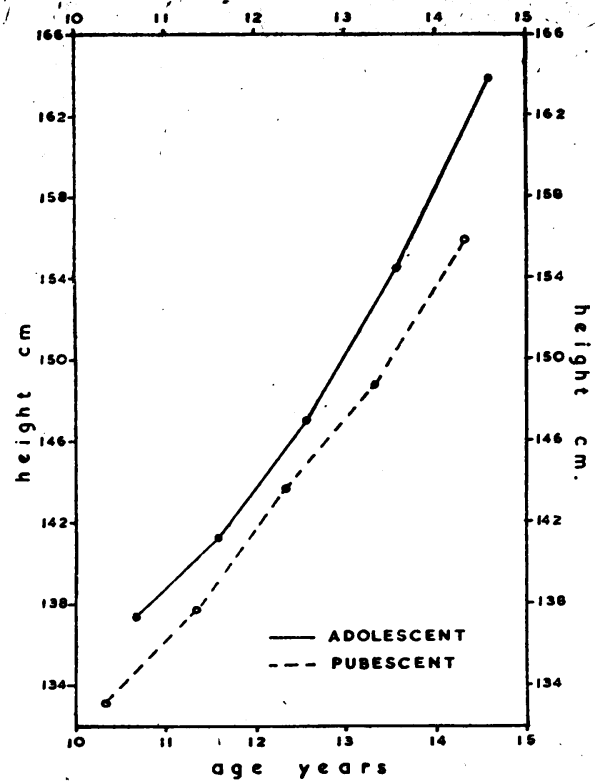

Fig. 7.

Figs. 7 and 8.-Mean height and weight of boys aged 14 to 15 at date of examination (School B), from eleventh to fifteenth year.

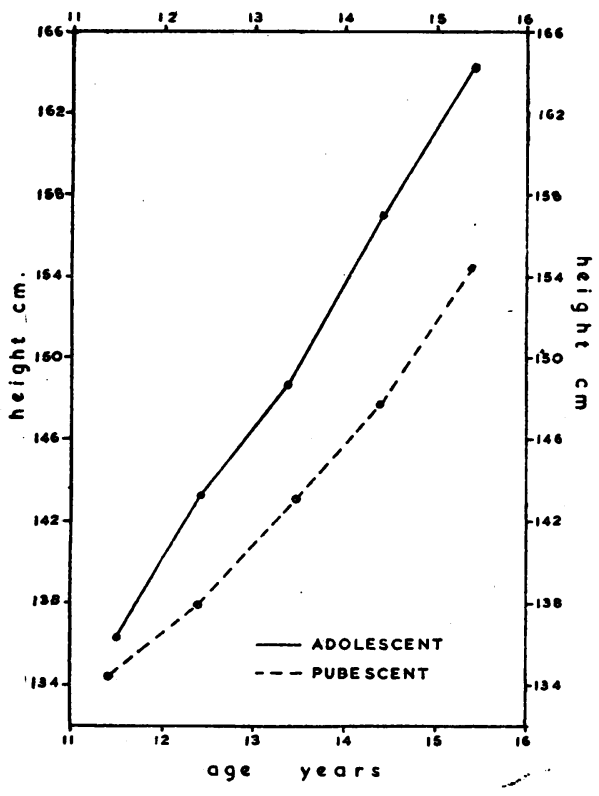

Fig. 9.

Fís. 9 and 10.-Mean height and weight of boys aged 15 to 16 years at date of examination (School B), from twelfth to to seventeenth year.

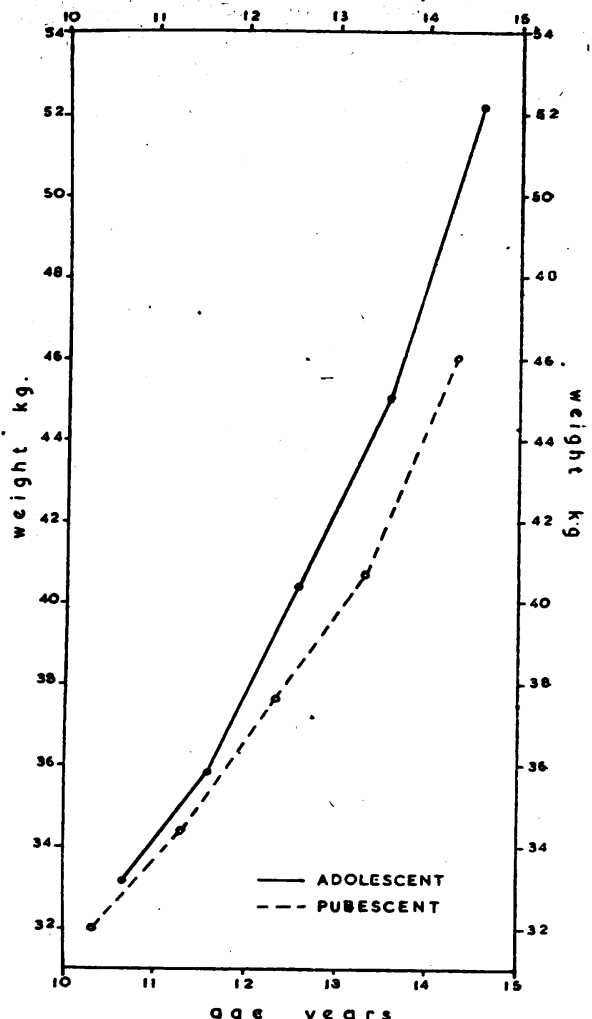

FIG. 8.

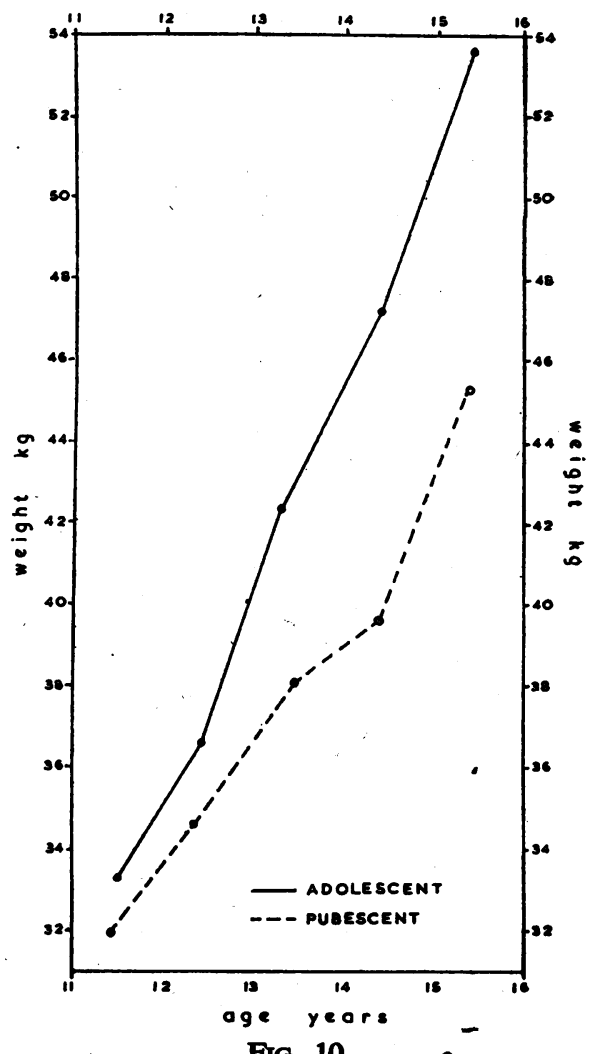

Fig. 10 
The growth curves of the prepubescent boys cannot, therefore, be expected to demonstrate clearly any changes in rate of growth which may be associated with the period immediately preceding the manifestations used in defining the 'pubescent' group. Similarly with the 'adolescent' group, which includes boys in whom maturity is well advanced but incomplete, and also a few boys in whom genital development has practically reached adult proportions, it might reasonably be objected that the grading is too wide to demonstrate changes peculiar to any one phase of development.

In the case of the 'pubescent' group, however, the phase of development is more clearly defined, and probably extends only over a period of six to nine months. Changes in rate of growth peculiar to this period might, therefore, be expected in the growth curves immediately before and after the date of examination. With the exception of the growth in height of the 12- to 13-year-old boys, examination of the growth curves does in fact suggest that there is an access of growth (more particularly in weight) in the year preceding the date of examination. Since, however, a somewhat similar increase in annual weight-gain is seen in the prepubescent boys aged 13 to 14 (School A), it was decided to reexamine this age-group approximately three months after the first examination, in order to determine whether there was any significant difference in the increase in height and weight of the pubescent and prepubescent boys aged 13 to 14 during this period.

The results as shown in table 4 were obtained.

There are, therefore, substantial differences between the increase in height and weight of the pubescent and prepubescent boys over the same period, and since the standard errors are relatively small, these differences can be regarded as significant. (The probability that the increase in height is greater for the prepubescent than for the pubescent boys is approximately 0.10 and in weight only 0.004 .) Since, however, the differences in increase in height between the two groups are not shown to the same extent in the increases in leg-length, these results are regarded primarily as an indication that further study along similar lines is likely to be fruitful.

Gynaecomastia. The presence of a small nodule of mammary tissue attached to the nipple (which could readily be distinguished on palpation from subcutaneous fat) was observed in twenty-six cases. In the great majority this was bilateral and painless or only very slightly tender. In no case could colostrum be expressed. In most cases where the mammary tissue was more than $2 \mathrm{~cm}$. in diameter, or where the chest was poorly covered, the swelling was visible as well as palpable, but no very marked case of breast enlargement was observed. The occurrence of gynaecomastia in relation to maturitygrading in the whole group was as follows:

\section{Total $\begin{gathered}\text { No. with } \\ \text { gynaecomastia. }\end{gathered}$}

$\begin{array}{lllrc}\text { Prepubescent } & . & 85 & 0 & 0 \\ \text { Pubescent ... } & . & 70 & 9 & 12 \cdot 9 \\ \text { Adolescent } & . & 53 & 17 & 32 \cdot 1\end{array}$

This would suggest that breast-development is more characteristic of the latter stages of puberty than the earlier, and is unlikely to be observed before other manifestations of sexual development. It is probable that gynaecomastia at puberty is due, as Weber (1946) expresses it, to " a temporary burst of endocrine activity in the testes and possibly in the adrenal cortex' and that the secretions of these organs contain not only adrogenic but some oestrogenic elements. These latter may be sufficient to produce temporary gynaecomastia in boys who are constitutionally so predisposed.

Relationship of terminal hair to genital development. In general, it was found that the appearance of pubic hair corresponded roughly with the stage of genital development classified as pubescent, though either might precede or follow the other; that axillary hair appeared relatively late, i.e. corresponding with the grading of adolescence ; and that hair on the linea alba was very late in appearance, being observed once only in the whole series. Whilst an exact analysis of the order of appearance of primary and secondary sexual characters could only be attempted by serial examinations of the same boys over a period of five or six years, the single examination, particularly of the pubescent boys, yielded certain information.

Of the boys classified as pubescent, 52 per cent. showed pubic hair (P1 to P3) and pubescent genital development, but no axillary hair ; 12 per cent. showed the same signs plus axillary hair (A1 or A2); 10 per cent. showed pubic hair with genitalia graded as prepubescent; and 23 per cent. showed pubescnt genitalia with absence of both pubic and axillary hair. In two cases, moderately profuse axillary hair was present in the absence of pubic hair, and with genitalia showing only the earliest signs of pubescence.

The adolescent group was almost evenly divided between those in which axillary hair was present and those in which it was absent. In all cases pubic hair was present, though this varied from P2 to P5. In

TABLE 4

MEAN INCREASE IN HEIGHT, LEG-LENGTH, AND WEIGHT OF PREPUBESCENT AND PUBESCENT BOYS AGED 13 TO 14 YEARS (SCHOOL A) OVER A PERIOD OF 100 DAYS

\begin{tabular}{l|c|c|c|c|c|c|c|c|c}
\hline & \multicolumn{3}{|c|}{$\begin{array}{c}\text { Increased height } \\
\text { (cm.) }\end{array}$} & \multicolumn{2}{|c|}{$\begin{array}{c}\text { Increased leg-length } \\
\text { (cm.) }\end{array}$} & \multicolumn{2}{c|}{$\begin{array}{c}\text { Increased weight } \\
\text { (g.) }\end{array}$} \\
\cline { 2 - 8 } & Mean & $\begin{array}{c}\text { Standard } \\
\text { error }\end{array}$ & $\begin{array}{c}\text { Standard } \\
\text { deviation }\end{array}$ & Mean & $\begin{array}{c}\text { Standard } \\
\text { error }\end{array}$ & $\begin{array}{c}\text { Standard } \\
\text { deviation }\end{array}$ & $\begin{array}{c}\text { Mean } \\
\text { Standard } \\
\text { error }\end{array}$ & $\begin{array}{c}\text { Standard } \\
\text { deviation }\end{array}$ \\
\hline Prepubescent & 1.51 & 0.15 & 0.579 & 1.23 & 0.26 & 1.045 & 439.43 & 138.91 & 552.83 \\
\hline Pubescent & 2.10 & 0.19 & 0.910 & 1.32 & 0.23 & 1.105 & $1,202.89$ & 178.96 & 853.62 \\
\hline
\end{tabular}


three cases, the growth of axillary hair appeared more advanced than that of pubic hair.

No relationship could be demonstrated between the occurrence of gynaecomastia and the presence of axillary hair.

Skin changes. It is generally recognized that the occurrence of comedones, acne, and possibly follicular keratosis are, or may be, related to the action of androgenic hormones. As already indicated, acne was seen in only a very small percentage of cases, whilst follicular keratosis appeared too variable in relation to season and exposure to be accurately correlated with puberty.

Comedones occurring on the facial area were, however, noted in 19.7 per cent. of the prepubescent group, 41.0 per cent. of the pubescent group, and 76.2 per cent. of the adolescent group.

\section{Discussion}

Whilst accurate maturity-grading of boys should include not only clinical examination but also radiological assessment of ossification and estimation of hormone-excretion, the present study indicates that grading on clinical grounds alone may serve to bring out certain differences in mean height and weight between the groups studied; and that such differences are present long before puberty is reached. If, as seems probable, there are also changes in rate of growth peculiar to the onset and duration of puberty, it follows that standard height and weight curves compiled without reference to the stage of maturity of the children measured will be deceptive when compared with the growth curves of an individual child; thus although the 13- to 14-year-old group contained the greatest number of pubescent boys, it was clear that the age of onset of puberty varied considerably in different subjects, and that in standard curves based on chronological age only, 'puberty-growth' will not be as clearly demonstrable at any one age-period as it may be in the individual. The relationship of puberty to increase in weight has also a practical importance when mean weight curves are used in the assessment of nutrition of communities of children in their teens, and it has previously been suggested (Ellis, 1945) that severe malnutrition may itself be responsible for a general delay in the onset of puberty, reflected in the shape of the mean weight curve of the affected groups.

Since the present study is concerned only with boys up to the age of sixteen, it gives no information with regard to the mean adult height and weight of those who mature early as compared with those who mature late. Studies made on girls and on adult women, in whom the age of onset of menstruation was known, indicated that the pyknic type tends to mature earlier (Pryor, 1936) and that the adult height of those who menstruated late tends to be greater than that of girls in whom the menarche occurs early. In order to obtain comparable information in the case of adult males, it would be necessary to follow up boys who had been examined and graded during their teens, since the age of onset of puberty is seldom accurately remembered or noted in their school medical records. However, if clinical assessment of maturity were included in the routine medical examination of boys, it would be possible to see whether adult height and weight showed any significant correlation with early or late maturity in the male. Whilst improvement on the clinical criteria employed in the present study could no doubt be made, it is suggested that they provide a simple, if rough, guide to maturity-grading which would serve this purpose.

Another possible application of maturity-grading is in relation to education and physical performance. Since education is based very largely on grouping by chronological age, it follows that most classes during the early and middle teens will contain boys varying from physically immature children to those who are well advanced in adolescence. Whilst intellectual development is obviously not commensurate with physical development, there are certain disadvantages in educating together boys of very different physical, and often emotional, stages of maturity. When large numbers have to be catered for, and classes have in any case to be subdivided on other than strictly intellectual grounds, it has been suggested that maturity-grading might be used as a basis of division, boys of roughly the same maturity then being educated together. With regard to physical performance, a natural division into maturity plus individual aptitude is more likely to establish itself automatically in athletics and organized games, but in the case of boys in employment, the burden may fall very unequally on the mature and the immature. Legislation with regard to juvenile employment of boys is entirely based on age, whereas in fact maturity is a better basis for deciding the physical demands that can be made on the individual. The raising of the school leaving-age to fifteen will have, amongst other advantages, the result that the proportion of prepubescent boys entering employment will be substantially reduced.

Whilst clinical maturity-grading applied to groups allows certain generalizations with regard to mean height and weight, it should, however, be emphasized that anthropometric measurements alone are an ureliable guide in the prediction of onset and duration of puberty in the individual. (Thus Flory (1935) in the case of girls found that anthropometric measurements were much inferior to radiological assessment of maturity in predicting the onset of menstruation.) It cannot be assumed that an individual child who is below the mean height and weight for his age will necessarily mature late rather than early. Similarly the rapidity with which individuals pass from one maturity-grade to the next is likely to vary considerably, and it follows that any application of maturity grading to educational grouping or employment can have only a limited and temporary value. The following example (not included in the present series) is quoted in detail, as it illustrates the early maturation of a small child and also the extremely rapid increase in height and weight which may take place at puberty.

M. J. was born prematurely at seven months, weighing $3 \frac{1}{2} \mathrm{lb}$. (1.59 kg.). At two months he weighed $6 \mathrm{lb}$. (2.73 kg.), at one year $19 \mathrm{lb}$. (8.6 kg.), 
at two years $24 \mathrm{lb}$. (10.9 kg.), and at four years $33 \mathrm{lb}$. $7 \mathrm{oz}$. $(15.2 \mathrm{~kg}$.). He was examined at the age of eleven years five months, when he was graded as prepubescent; he then weighed $68 \mathrm{lb}$. $(30.9 \mathrm{~kg}$.) and measured $4 \mathrm{ft} .6 \mathrm{in}$. $(137 \cdot 2 \mathrm{~cm}$.) in height. At twelve years two months he showed the presence of pubic hair (P2) and early genital development, and was graded as pubescent. At twelve years five months he had reached 'established adolescence'; the voice was broken, pubic hair was profuse, axillary hair was present, and the 'adolescent moustache' was appearing on the upper lip. His height was $5 \mathrm{ft}$. $1 \frac{1}{2}$ in. $\left(156 \cdot 2 \mathrm{~cm}\right.$.) and weight $105 \frac{1}{2}$ lb. $(48.0 \mathrm{~kg}$.). He had, therefore, not only matured early (receiving a higher maturity-grading at twelve years five months than any of the boys in the 12- to 13-year-old group), but had passed from prepuberty to adolescence in the space of one year, during which time he had increased $7 \frac{1}{2}$ in. $(19 \mathrm{~cm}$.) in height and $37 \frac{1}{2} \mathrm{lb}$. (17 kg.) in weight. Apart from vasovagal attacks, coincident with the onset of puberty, he appeared healthy, and no pathological cause for his rapid growth and development was found.

\section{Summary and Conclusions}

1. Two hundred and eight boys, aged eleven to sixteen years, from two residential schools, were graded on a basis of clinical assessment into three maturity-groups viz. prepubescent, pubescent, and adolescent. Comparison was made between the mean heights and weights of boys from the same school who fell into the same yearly age-groups but into different maturity-groups.

2. It was found that not only were boys of the higher maturity-group heavier and taller than their contemporaries in the lower maturity-group, but that differences between the growth curves could be demonstrated as far back as the sixth year (in the case of boys from School A, where records were available to this time).

3. The growth curves suggested that there was an increased annual gain in weight, and to a lesser extent in height, which could be related to the onset and duration of puberty.

4. This was confirmed by the re-examination of one age-group after a period of one hundred days, when it was found that increase in height and weight of pubescent boys was significantly greater than that of prepubescent boys in the same school.

5. Gynaecomastia was observed in none of the prepubescent group; in 12.9 per cent. of the pubescent group ; and in 32.1 per cent. of the adolescent group.

6. Observations were made on the relationship of certain primary and secondary sexual characters during puberty.

I wish to thank the Governing Bodies and Headmasters of the Thomas Coram School and the Royal Merchant Navy School for facilities in carrying out this investigation, which was undertaken from the Department of Child Health, Guy's Hospital. I also wish to thank the Medical Officers and Nursing Staffs of the two schools for their help and cooperation.

\section{REFERENCES}

Catchpole, H. R., Greulich, W. W., and Sollenberger, R. T. (1938). Amer. J. Phisiol., 123, 32.

Ellis, R. W. B. (1945). Arch. Dis. Childh., 20, 97.

Flory, C. D. (1935). Child Development, 6, 1.

Godin, P. (1934). Quoted by Laroche, G. (1938). La Puberté. Paris.

Greulich, W. W., Doriman, R. I., Catchpole, H. R., Solomon, C. I., and Culotta, C.S. (1942). Somatic and Endocrine Studies of Puberal and Adolescent Boys. Nat. Res. Council, Washington.

Nathanson, I. T., Towne, L. E., and Aub, J. C. (1939). Endocrinol., 24, 335. (1941). Ibid., 28, 851.

Pryor, H. B. (1936). J. Pediat., 8, 52.

Stone, C. P. and Barker, R. G. (1937). Human Biol., 9,1 .

Talbot, N. B. Butler, A. M., Berman, R. A., Rodriguez, P. M., and MacLechann, E. A. (1943). Amer. J. Dis. Child., 65, 364.

Weber, F. P. (1946). Rare Diseases and some Debatable Subjects. London. 